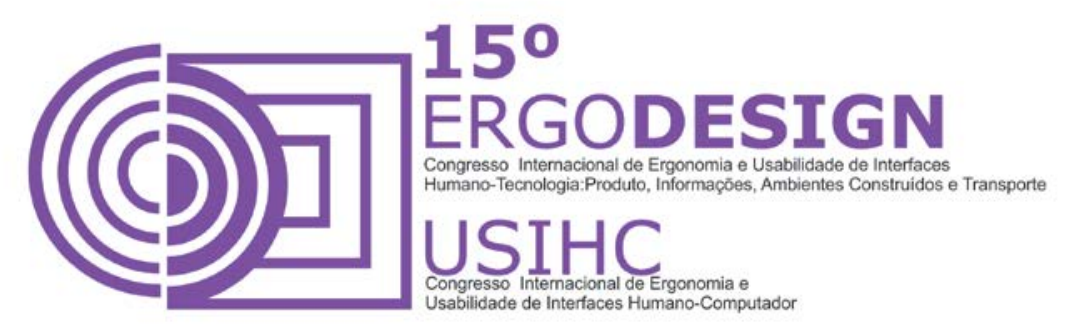

\title{
CONTRIBUIÇÃO ERGONÔMICA PARA UM TRANSPORTE PÚBLICO HUMANIZADO: UM ESTUDO NOS TERMINAIS DO GRANDE RECIFE
}

\section{ERGONOMIC CONTRIBUTION TO A HUMANIZED PUBLIC TRANSPORTATION SYSTEM: A STUDY IN RECIFE'S BUS TERMINALS}

\author{
SEABRA, Sadi Filho Autor (1); \\ MARTINS, Laura Bezerra (2) \\ (1) Universidade Federal de Pernambuco - UFPE, Mestrando em Design \\ e-mail:sadi@sadiseabra.com \\ (2) Universidade Federal de Pernambuco - UFPE, Doutora \\ e-mail:bmartins.laura@gmail.com
}

\begin{abstract}
RESUMO
O Sistema Estrutural Integrado (SEI) é uma rede responsável pelo transporte urbano público da cidade do Recife-PE e região metropolitana. Composto por linhas de ônibus e metrô interligadas por terminais de integração, que foram concebidos para facilitar a vida dos passageiros e otimizar o transporte. A pesquisa determinou diretrizes relacionados à ergonomia do ambiente construído desse espaços, visando melhores condições de conforto, usabilidade, acessibilidade e segurança aos usuários. A avaliação dos ambientes construídos aliadas a percepção dos usuários foram capazes de identificar e mapear os problemas ergonômicos e de acessibilidade que são causadores de desagradáveis situações para a população.

Palavras-chave: Ergonomia do Ambiente Construído; Terminais Integrados; Acessibilidade; Transporte Público.

\footnotetext{
ABSTRACT

The Integrated Structural System (SEI) is the network of the urban public transport in the city of Recife and the metropolitan area. It consists on buses and subway lines interconnected by integration terminals specially created to make life easier for passengers. This research had aimed to establish guidelines to improve the ergonomics of the environment built (the Integrated Terminals) to improve the conditions of comfort, usability, accessibility and safety of their users. The analysis of the these environments combined with the perception of the users were able to identify and show in detail the ergonomic and accessibility problems, raising critical points that are repeated in the terminals and are causing unpleasant situations for the people.
} 


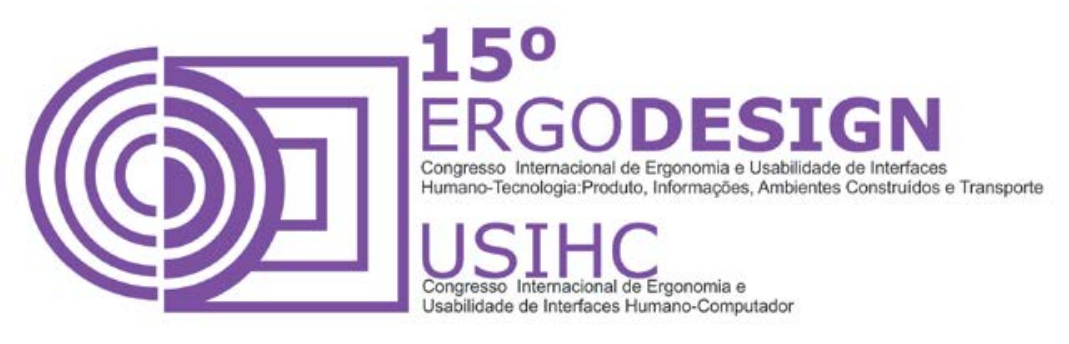

Keywords: Built Environment Ergonomics; Integrated Terminals; Accessibility; Public Transportation.

\section{INTRODUÇÃO}

Os terminais Integrados do Grande Recife fazem partem do Sistema Estrutural Integral (SEI) responsável pelo transporte urbano da cidade do Recife e região metropolitana, foram criados com a intenção de facilitar a vida do usuário do transporte público do Recife, deixando os trajetos mais longos um pouco, entretanto mais baratos e integrando diferentes pontos do Grande Recife.

Esses terminais são ambientes construídos do transporte público responsáveis por realizar o transbordo dos passageiros diariamente de um ônibus para outro. Esses espaços comportam diversas outras atividades realizadas tanto pelos funcionários como pelos passageiros, ou seja, gera uma interação entre os usuários e o terminal. A pesquisa baseia-se nos constrangimentos oriundos dessas relações.

Como se torna difícil, nos quesitos custo e tempo, realizar uma avaliação ergonômica em cada um dos 18 Terminais Integrados do Grande Recife, foi realizado um estudo em 3 deles, a amostra foi determinada de acordo com a quantidade de usuários, localização e data de edificação do terminal. O tema dessa investigação se enquadra na área de Ergonomia com um estudo aprofundado em ambiente construído e a relação de conforto e desempenho dos usuários e funcionários do Terminal Integrado do Grande Recife. Este artigo é um recorte de uma pesquisa maior de mestrado.

O estudo nos Terminais Integração - TI, verificou se eles são adequados às condições e limitações humanas e se foram concebidos sob bases que consideram a ergonomia. Além de determinar parâmetros para adequações e intervenções de melhoria ergonômica dos terminais, confirmando importância da realização desses estudos para que a ampliação do sistema de integrações se torne cada vez mais voltadas às necessidades físicas, cognitivas dos usuários.

\section{CONTEXTUALIZAÇÃO}

O desafio do transporte Público Coletivo é proporcionar um nível de qualidade do serviço que satisfaça as expectativas de seus usuários, com preços acessíveis e conforto, pois 95\% da demanda atual de transporte público é atendida por ônibus (MDT, 2009). Devendo, portanto, o governo se mobilizar para subsidiar os custos de transporte público de qualidade.

Diversos protestos ocorreram em 2013 no Brasil, a motivação inicial dessas mobilizações começou com o aumento de 20 centavos na tarifa de ônibus do transporte público da cidade de São Paulo. Os protestos foram ganhando grandes proporções e se alastrando por diversas cidades de toda a nação causando a paralisação de setores do país como comércio, transportes, escolas, portos entre outros. A insatisfação pelo preço abusivo cobrado na maioria das cidades foi a gota d'água para que o povo olhasse as deficiências da mobilidade existente em suas cidades, exigindo assim mais qualidade no transporte público. 


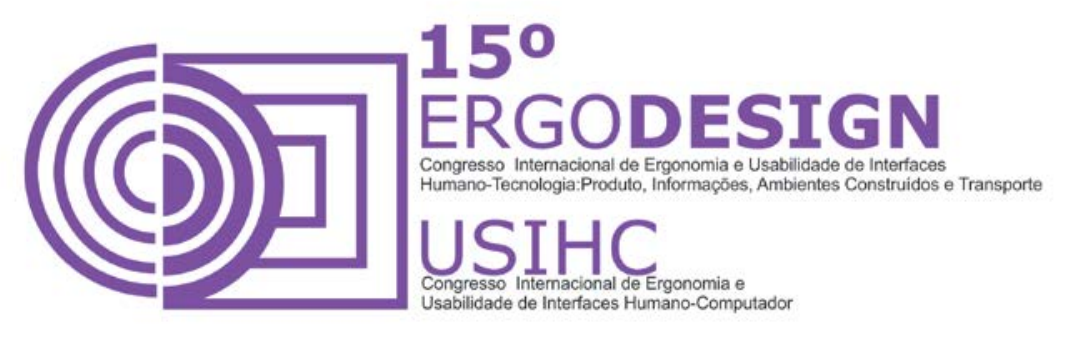

De acordo com Furtado (2013) a questão do aumento da tarifa foi apenas um estopim para um problema que a muito é reprimido no Brasil: a melhoria e expansão do transporte público nas grandes cidades brasileiras. Para o mesmo autor precisa-se de uma prioridade do governo em investimentos em mobilidade que garantam o direito de ir e vir de todos.

Cadaval (2014) relata em seu artigo que o sociólogo Manuel Castells, um dos principais estudiosos das manifestações sociais contemporâneas, escreveu algumas anotações em seu livro "Redes de indignação e esperança" que a imobilidade estrutural das metrópoles brasileiras seria resultado do modelo caótico de crescimento urbano produzido pela especulação imobiliária, pela corrupção municipal e o transporte sendo tratado como escravo da indústria do automóvel.

Para lida (2005) com a avaliação do ambiente é realizado o diagnóstico ergonômico que identifica os motivos pertinentes aos problemas encontrados na demanda, correlacionados ao trabalho e à empresa, diante disso realizar uma intervenção ergonômica em um Terminal Integrado de Passageiros, além de identificar diversos problemas de caráter ergonômico, problemas de acessibilidade e segurança pode ainda aumentar e melhorar o desempenho das atividades, assim como de forma direta tornar mais confiável o serviço prestado pelas empresas concessionárias dos ônibus que utilizam esses terminais.

A ergonomia do ambiente construído consiste na adaptabilidade ergonômica de um espaço, incluindo o atendimento aos anseios dos usuários, nos diversos aspectos e sentimentos que a configuração do espaço pode provocar. Para um ambiente ser considerado ergonomicamente adequado deve ser adotada uma abordagem sistêmica e devem ser observados vários aspectos, tais como: acessibilidade; conforto acústico; conforto térmico; conforto lumínico; layout e postos de trabalho; mobiliário; percepção do usuário; revestimentos; segurança (VILLAROUCO 2009).

Para Martins et al (2006) a ergonomia do ambiente construído estuda a relação humana nas suas interações com o espaço construído, incorporando áreas do conhecimento relacionado ao ser humano como: antropologia, antropometria, psicologia, semiótica e áreas do conhecimento relacionada ao ambiente físico como: a arquitetura, engenharia, design, de modo a considerar as interações e adequações ao ser humano.

De acordo com o Consórcio de Transportes do Grande Recife os terminais integrados são fechados e proporcionam aos usuários um ambiente limpo, seguro e confortável possuindo equipamentos como lanchonetes, lojas, funcionários treinados para funções específicas (como segurança e vigilância) que facilitam a utilização do Sistema por parte dos usuários. Entretanto, o que se vê nos jornais de grande circulação do Estado são diversas reclamações que questionam a qualidade do transporte coletivo e mostram o sofrimento da parcela da população que enfrenta diariamente os TIGR.

Na Região Metropolitana do Recife são 18 terminais de integração de ônibus por onde circulam em média um milhão de pessoas e são várias as reclamações dos que utilizam o serviço. Elas vão desde as filas enormes, confusão para entrar nos ônibus lotados, muito tempo de espera nos pontos de ônibus, falta de acessibilidade física, desinformação quanto ao percurso do 


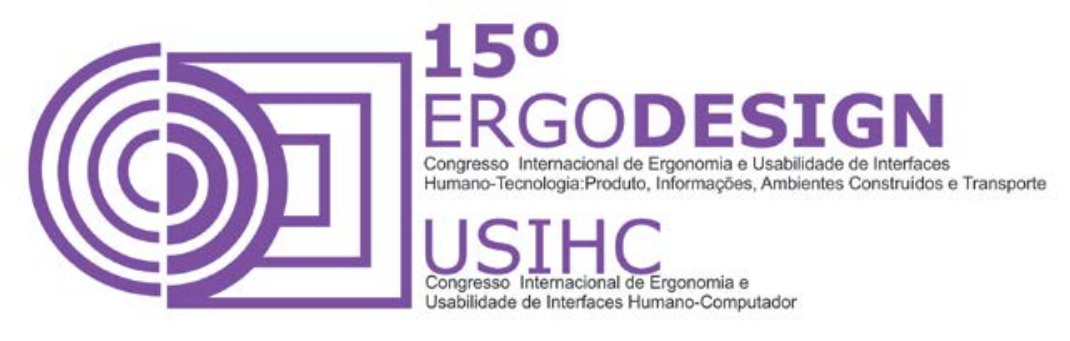

coletivo, entre outros constrangimentos. São necessários que estudos que estruturem e normalizem a construção desses espaços para evitar situações indesejadas aos usuários.

\section{METODOLOGIA}

Os métodos e técnicas que foram utilizados nesta pesquisa têm como base três metodologias bem difundidas: APO - Avaliação Pós Ocupação, MEAC - Metodologia Ergonômica para o Ambiente Construído e a SHTM - Intervenção Ergonomizadora, pois essas metodologias utilizam de observações, registros comportamentais, escalas de avaliação e questionários, estudos de layout espacial através de um modelo e percepção do usuário.

As etapas de pesquisa foram: Entendimento do sistema de transporte, no qual foram estudados as normas e sistema de operação do SEl; Reconhecimento do ambiente construído, através de plantas arquitetônicas dos terminais, elementos construtivos, equipamentos/mobiliários e medições de conforto ambiental; Avaliação do ambiente em uso, verificando os fluxos, postos de trabalho, atividades realizadas, acessibilidade, horários de funcionamento, turnos de trabalho, setorização; Percepção do usuário, onde foram entrevistados 408 usuários que responderam itens sobre manutenção, estrutura, operação, comunicação, segurança e conforto ambiental. Os dados obtidos na pesquisa de percepção, de acordo com Bolfarine (2005), têm 95\% de confiabilidade.

Finalmente, a avaliação se encerra com o diagnóstico da situação estudada. Nessa etapa, todos os elementos coletados estão presentes e é realizado o confronto entre o resultado das observações realizadas, das interações com os diversos atores investigados e da percepção dos usuários e depois são propostas as diretrizes com base nos problemas detectados.

\section{OBEJTO DE ESTUDO E RESULTADOS}

Os três terminais estudados foram selecionados por serem os mais importantes da sua localidade são eles: Terminal Integrado Tancredo Neves com sua localização na Imbiribeira, Zona Sul do Recife foi inaugurado em março de 2013; O terminal Pelópidas Silveira que é o maior terminal da Região Metropolitana do Recife, e o que possui o maior fluxo de pessoas por dia, localizado em Paulista, foi em inaugurado em 2009; O Terminal Integrado da Macaxeira o mais antigo que foi inaugurado em 1992, localiza-se entre os bairros de Dois Irmãos e da Macaxeira.

\subsection{Entendimento do Sistema de transporte}

Nesta etapa a pesquisa verificou o funcionamento do transporte público do recife através das suas normas internas e organização. De acordo com o manual de operação do Consórcio Grande Recife os terminais, pontos de troca e estações SEI devem ser planejados e projetados com objetivo de minimizar os tempos, transtornos, e inconveniências do transbordo nas integrações; reduzir os esforços físicos despendidos entre as plataformas de desembarque e de embarque; maximizar as condições de conforto, qualidade ambiental e de segurança do espaço 


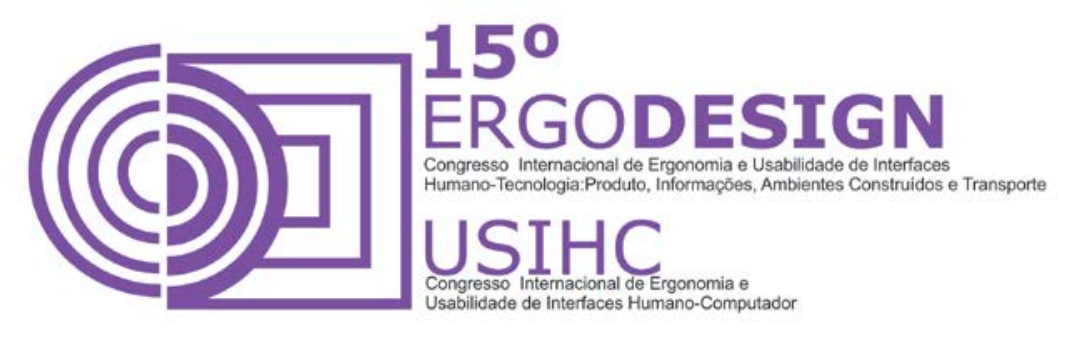

utilizado com circulação de pedestre sempre em plataforma para evitar que haja conflito com os veículos.

\subsection{Reconhecimento do ambiente a ser avaliado e reconhecimento do ambiente em uso}

Nesta etapa procurou-se entender o ambiente construído o seu funcionamento e em sequencia mapear os problemas ergonômicos.

Os terminais encerram suas atividades em média das $1 \mathrm{~h}$ às $4 \mathrm{~h} 30$, funcionando durante 20 horas e 30 minutos todos os dias. Os horários de maior fluxo de passageiros são de $6 \mathrm{~h}$ as $9 \mathrm{~h}$ e de $17 \mathrm{~h}$ as $20 \mathrm{~h}$. De acordo com a administração dos terminais, o tempo de intervalo entre os ônibus ocorre entre 10 minutos e 1 hora.

Nas tabelas 1 e 2 são apresentados dados que foram fundamentais para a análise dos terminais.

Tabela 1 - Frota e viagens

\begin{tabular}{ccccc}
\hline Terminal & Linhas & Frota & Viagens & Usuários por dia \\
\hline Macaxeira & 13 & 152 & 1498 & 60.000 \\
Tancredo Neves & $26 \mid$ metrô & 152 & 1732 & 43.000 \\
Pelópidas Silveira & 21 & 138 & 1927 & 69.000 \\
\hline
\end{tabular}

Fonte: Grande Recife

Tabela 2 - Áreas, formatos e características de acesso nos Terminais Integrados Macaxeira, Tancredo Neves e Pelópidas Silveira.

\begin{tabular}{|c|c|c|c|c|}
\hline Terminal & $\begin{array}{l}\text { Área do } \\
\text { terreno }\end{array}$ & $\begin{array}{c}\text { Área } \\
\text { construída }\end{array}$ & Formato & Acesso \\
\hline Macaxeira & $10.650 \mathrm{~m}^{2}$ & $2.875 \mathrm{~m}^{2}$ & Circular & $\begin{array}{l}1 \text { entrada/saída de veículos; } \\
1 \text { entrada/saída pedestre. }\end{array}$ \\
\hline $\begin{array}{l}\text { Tancredo } \\
\text { Neves }\end{array}$ & $12.880 \mathrm{~m}^{2}$ & $3.350 \mathrm{~m}^{2}$ & Retangular & $\begin{array}{l}1 \text { entrada de veículos; } \\
1 \text { saída de veículos; } \\
1 \text { entrada/saída de pedestres (via } \\
\text { pública); } \\
1 \text { entrada/saída pedestre por metrô. }\end{array}$ \\
\hline $\begin{array}{l}\text { Pelópidas } \\
\text { Silveira }\end{array}$ & $32.580 \mathrm{~m}^{2}$ & $5.452 \mathrm{~m}^{2}$ & $\begin{array}{l}\text { Retangular } \\
\text { (longilíneo) }\end{array}$ & $\begin{array}{l}2 \text { entradas/saídas de veículos; } \\
2 \text { entradas/saídas pedestre. }\end{array}$ \\
\hline
\end{tabular}

\section{Fonte: Grande Recife, adaptado pelo autor}

Dividindo a quantidade de usuários pelo número de viagens realizadas por terminal obtém-se um valor médio de pessoas por ônibus, claro se for considerada a distribuição homogênea de 


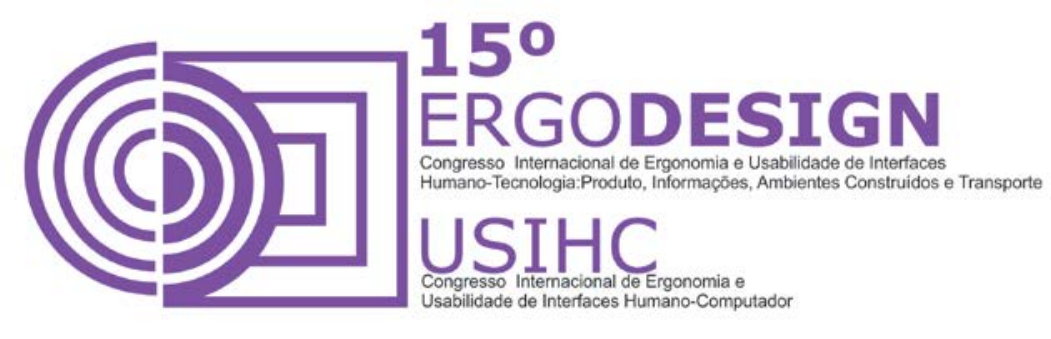

pessoas em todos os horários. No terminal da Macaxeira verifica-se uma média de 40 usuários por ônibus em cada viagem, no terminal Tancredo Neves tem-se uma média de 24,8 usuários e no terminal de Pelópidas Silveira verifica-se 35,8 passageiros por ônibus. O que demostra uma falta de planejamento especializado além da necessidade de um estudo projetual, pois os terminais possuem características de formato, área construída e de terreno bem diferentes, sem possuir um padrão estabelecido.

Com a observação das características físicas foi verificada a falta de manutenção especializada em todos os terminais estudados. Constatou-se também a presença de vandalismo, que é percebida facilmente nos banheiros. Outros problemas foram notados, tais como relativos à segurança e proteção contra incêndio, que é feita por extintores e hidrantes, nos quais alguns extintores não estão nos locais onde há sinalização e alguns estão fora do prazo de validade; o terminal também não possui sinalização de emergência, nem instruções em caso de acidentes.

\subsubsection{Setorização}

A setorização foi definida junto com os gestores dos terminais que através de um passeio acompanhado explicaram o funcionamento do sistema, bem como suas atividades, a partir desse mapeamento podem-se reconhecer as áreas de atividade e avalia-las de forma direcionada formando um padrão entre os terminais. Na figura 1 é apresentada a planta do terminal da macaxeira demostrando o estudo realizado nos terminais onde foram divididos por setores para a melhor identificação e entendimento do funcionamento e visualização de sua estrutura física.

Figura 1 - Setorização do Terminal da Macaxeira
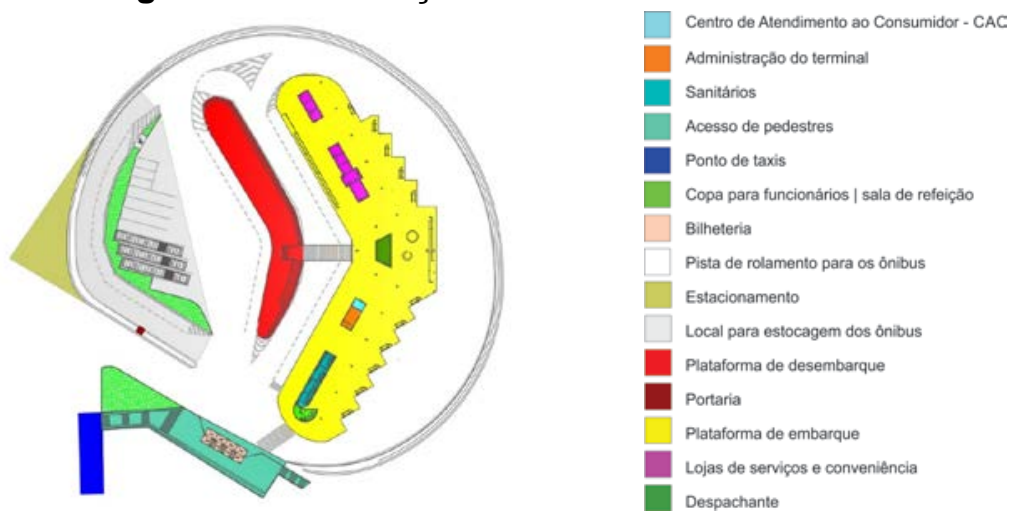

Fonte: Grande Recife, adaptado pelo autor

\subsubsection{Funcionários do terminal}

Em cada terminal foram realizados levantamentos dos funcionários que são de responsabilidade do Consórcio Grande Recife foram estudadas as funções, a quantidade de funcionários e os horários de cada funcionário que são responsáveis pelo funcionamento desse ambiente construído. No levantamento dos funcionários foram realizadas entrevistas que 


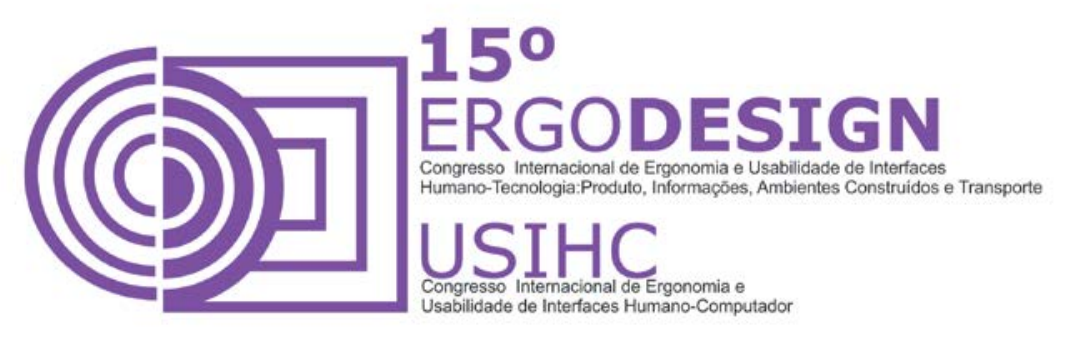

identificaram os principais problemas enfrentados por eles na execução de suas atividades relacionadas ao ambiente e operação do terminal.

\subsubsection{Fluxos}

Os fluxos foram realizados com base na observação "in loco" e com informações vindas dos gestores dos terminais que informaram os pontos de desembarque, embarque, acessos de pedestres e percurso dos ônibus. Na figura 2 é apresentando o estudo do fluxo de pessoas e de coletivos realizados dentro dos terminais de integração. Esses estudos têm como objetivo perceber o caminho feito pelos usuários, áreas de circulação cruzada, fluxo principal e secundário, riscos de colisão com veículos e podem ser apoio para pesquisas de sinalização.

Figura 2 - Fluxos de pessoas e coletivos nos Terminais Integrados: Tancredo Neves

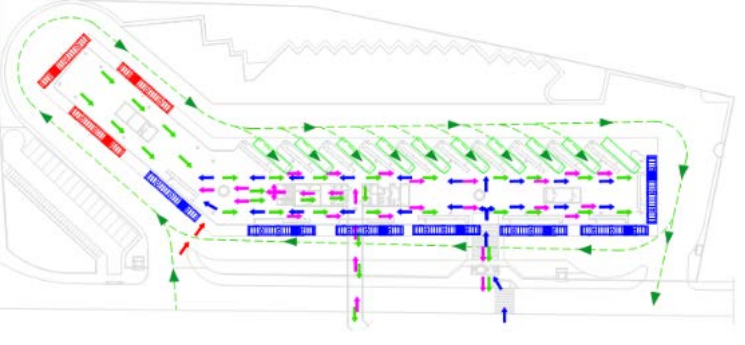

Fonte: Grande Recife, adaptado pelo autor.

\subsubsection{Problematização Ergonômica}

Esta etapa compreendeu a avaliação ergonômica dos três terminais, dividida por setores. A avaliação destrincha os principais pontos de dificuldades, consequências dos problemas citados e quais os terminais em que os mesmos foram verificados. A problematização ergonômica está elucidada no quadro 1, ela foi realizada em todos os setores de cada terminal. Foram acrescentadas aos quadros fotos reais dos locais estudados, ilustrando algumas das dificuldades relacionadas à ergonomia nos terminais. A seguir é apresentado um dos quadros estruturados da pesquisa maior.

Quadro 1 - Avaliação ergonômica da área de embarque nos terminais Macaxeira, Pelópidas Silveira e Tancredo Neves.

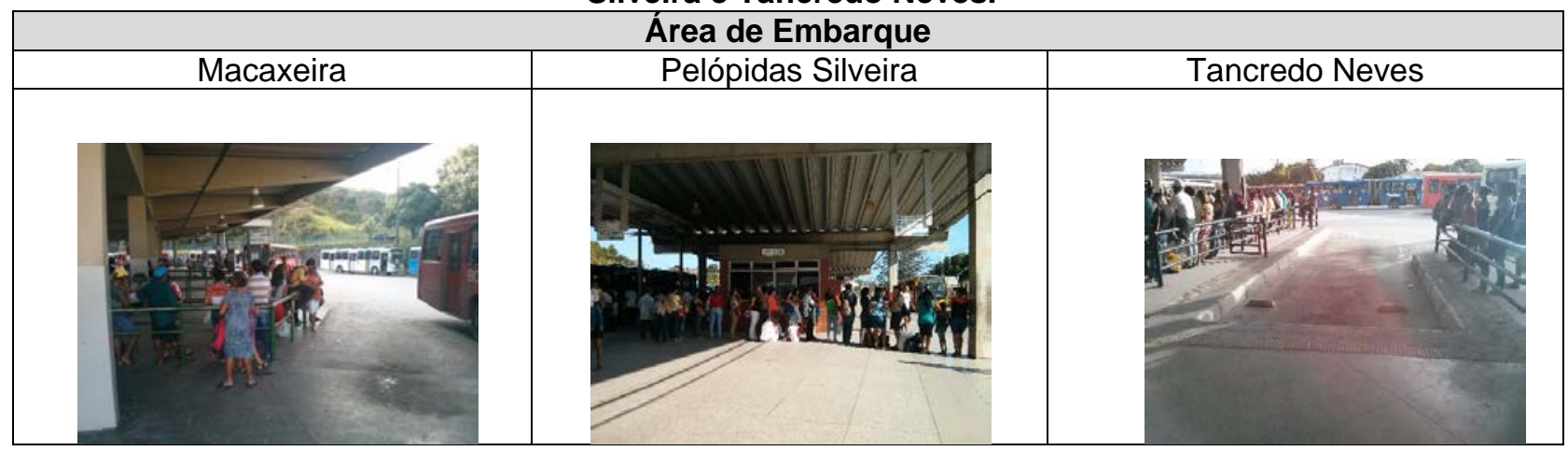




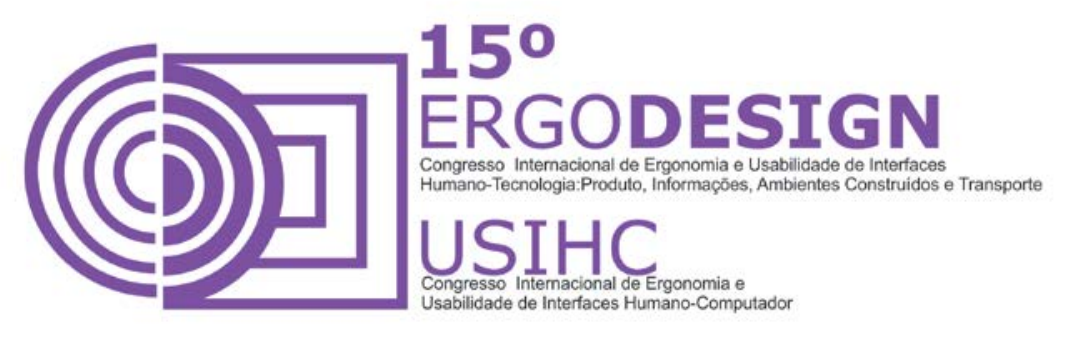

\begin{tabular}{|c|c|c|}
\hline \multicolumn{3}{|c|}{ Avaliação Ergonômica } \\
\hline Pontos de dificuldade & Consequências & Terminal \\
\hline $\begin{array}{l}\text { As áreas de embarque com filas } \\
\text { reservadas para prioridades } \\
\text { (idosos, deficientes, gestantes) } \\
\text { não são respeitadas nem } \\
\text { sinalizadas. }\end{array}$ & $\begin{array}{l}\text { Essa desorganização causa tumulto na entrada dos } \\
\text { ônibus, estresses e discussões entre os usuários. } \\
\text { Falta respeito às pessoas que têm prioridade. }\end{array}$ & Todos \\
\hline $\begin{array}{l}\text { Os usuários utilizam o } \\
\text { organizador de filas para sentar. }\end{array}$ & $\begin{array}{l}\text { Por não ser um local projetado para ser utilizado } \\
\text { como assento, o usuário pode cair gerando um } \\
\text { acidente. }\end{array}$ & Todos \\
\hline $\begin{array}{l}\text { A plataforma não possui uma } \\
\text { indicação de área segura que } \\
\text { não deve ser ultrapassada no } \\
\text { piso. }\end{array}$ & $\begin{array}{l}\text { Os usuários esperam pelos ônibus, muitas vezes, na } \\
\text { pista de rolamento, correndo o risco de } \\
\text { atropelamento, ou na beira da plataforma, podendo } \\
\text { cair na pista de rolamento. }\end{array}$ & Todos \\
\hline $\begin{array}{l}\text { Os organizadores de fila não têm } \\
\text { o comprimento compatível com } \\
\text { os tamanhos das filas. }\end{array}$ & $\begin{array}{l}\text { São utilizados cavaletes e cordas para delimitar as } \\
\text { filas, pois em horários de pico as filas se misturam, } \\
\text { causando desorientação nos passageiros. As filas } \\
\text { desorganizadas obstruem as áreas de passagem. }\end{array}$ & Todos \\
\hline $\begin{array}{l}\text { Placas de sinalização } \\
\text { quebradas, com informações } \\
\text { sem validade ou com remendos } \\
\text { feitos a mão e de papel. }\end{array}$ & $\begin{array}{l}\text { As placas quebradas e/ou com informações erradas } \\
\text { causam desorientação aos usuários menos } \\
\text { experientes. }\end{array}$ & $\begin{array}{l}\text { Macaxeira } \\
\text { Pelópidas } \\
\text { Silveira }\end{array}$ \\
\hline $\begin{array}{l}\text { Há um espaço grande e uma } \\
\text { diferença de nível entre a } \\
\text { plataforma e o ônibus. }\end{array}$ & $\begin{array}{l}\text { Gera um risco de acidente e dificuldade de } \\
\text { embarque, principalmente para idosos e pessoas } \\
\text { com dificuldade de locomoção. }\end{array}$ & Todos \\
\hline $\begin{array}{l}\text { Ausência de batedor no pneu } \\
\text { dos ônibus. }\end{array}$ & $\begin{array}{l}\text { Algumas baias de embarque estão sem o batedor } \\
\text { que avisa ao motorista o local exato de parar, } \\
\text { podendo gerar um risco de atropelamento e } \\
\text { deixando as portas em desencontro com o local de } \\
\text { embarque. }\end{array}$ & Todos \\
\hline $\begin{array}{l}\text { Não há uma área indicada para o } \\
\text { embarque das prioridades. }\end{array}$ & Problema de acessibilidade e inclusão. & Todos \\
\hline
\end{tabular}

Fonte: autor.

\subsubsection{Condições ambientais}

Nessa etapa foram aferidos em diversos setores a temperatura, o índice de ruídos e a iluminância para confrontá-los com os indicadores das normas. Utilizou para isso equipamentos de precisão do laboratório de Ergonomia do Ambiente Construído - EAC da UFPE. Os equipamentos utilizados foram um luxímetro - Digital LUX METER da Minipa modelo MLM1011; um sonômetro - Decibelímetro Digital também da Minipa modelo MSL-1325; e um Termo Anemômetro Digital da Minipa modelo MDA-11.

Com os dados, observou-se que alguns postos de trabalho estão bastante comprometidos como portaria e bilheteria, pois possuem temperatura acima do que a norma recomenda. Durante a noite verifica-se que em certos locais do terminal da Macaxeira a iluminância está muito abaixo do recomendado podendo gerar o risco de acidentes. Quanto a incidência dos 


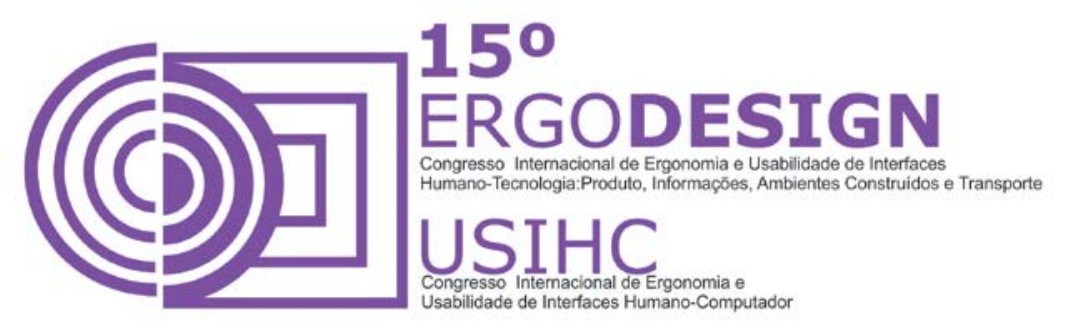

ruídos verifica-se que praticamente todos os locais tem estão acima de $60 \mathrm{~dB}(\mathrm{~A})$ que não prejudica a saúde, entretanto causa bastante interferências na comunicação e estresses.

\subsubsection{Percepção do Usuário}

Foi realizada a pesquisa com 408 usuários nos 3 terminais selecionados. De acordo com Bolfarine (2005), há uma confiabilidade de $95 \%$ nos dados obtidos. Os itens desse questionário foram agrupados em 6 grupos: No grupo 1 são avaliados a estrutura física e manutenção do terminal ; No grupo 2 são avaliados os itens relacionados a operação e organização do terminal; No grupo 3 são avaliados os itens relacionados ao conforto ambiental do terminal; No grupo 4 são avaliados os itens relacionados aos serviços oferecidos no terminal; No grupo 5 são avaliados os itens relacionados as informações e comunicação: No grupo 6 são avaliados os itens relacionados à estrutura da segurança e posicionamento dos funcionários quanto a segurança.

Foi ainda perguntada aos usuários qual a melhoria, na opinião dele, mais necessária e urgente para o terminal. Era solicitado que o usuário dissesse livremente a alternativa e o pesquisador encaixaria a resposta dentre as opções apresentadas no gráfico 1 a seguir.

\section{Gráfico 1 - Melhorias necessárias e urgentes, na ótica do entrevistado, para os Terminais Integrados Tancredo Neves, Pelópidas Silveira e Macaxeira.}

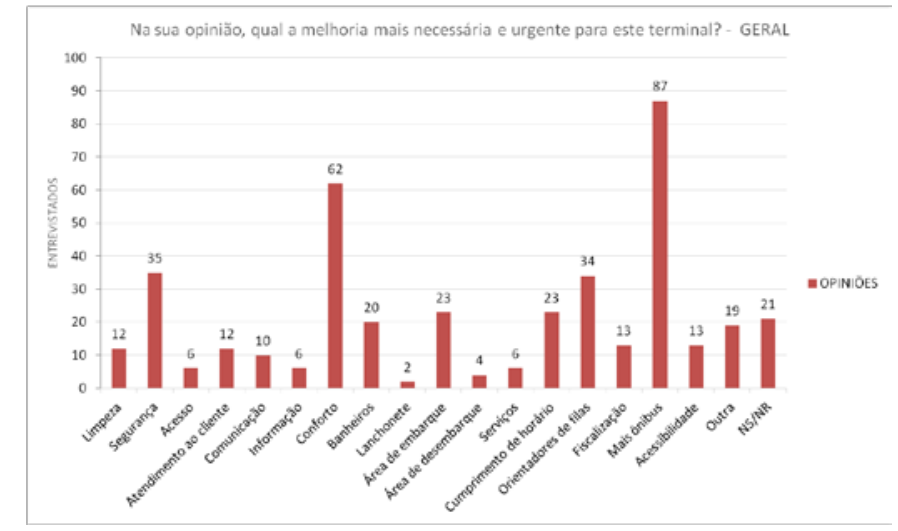

Fonte: autor

Com essa pesquisa de percepção do usuário foi fácil perceber os pontos de insatisfação causados por esses terminais aos usuários, bem como a necessidade de um transporte mais ágil, confortável, seguro e organizado. A pesquisa de percepção favoreceu a pesquisa, pois mostrou pontos de desconformidade não percebidos pelo especialista, bem como fundamentou outros identificados.

\section{Diretrizes}




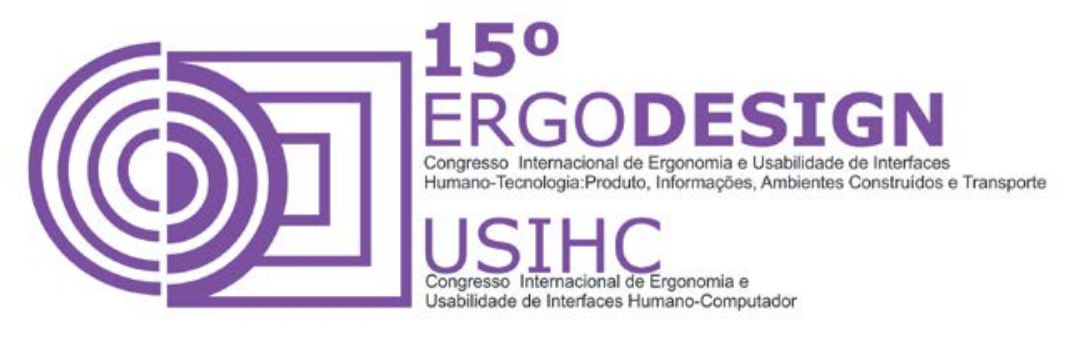

Com o mapeamento de todos os constrangimentos ergonômicos foram descritas diretrizes realizadas com base em toda a pesquisa. Elas foram classificadas em diretrizes de projeto e adequação que estão relacionadas as questões estruturais e de adequação de situações em adequação nos terminais; e diretrizes operacionais. A seguir são apresentadas algumas delas:

- O posto de trabalho das bilheterias, da portaria, do CAC, e sala do gestor devem proporcionar aos funcionários um ambiente com temperatura entre $20^{\circ}$ e $23^{\circ}$, com ruídos entre $35 \mathrm{~dB}(\mathrm{~A})$ a 45 $\mathrm{dB}(\mathrm{A})$, sem a incidência direta dos raios solares, com iluminamento de 300 lux a 750 lux e mobiliário confortável/adequado a atividade.

- A sala do gestor deve conter um sistema de controle do terminal através de câmeras e circuito interno de TV, interligado com todos os monitores do terminal e uma central de controle do Consórcio Grande Recife. Além de um sistema de som para comunicação com os passageiros e funcionários.

- As faixas de pedestre devem ser sinalizadas, ter piso tátil guia, possuir semáforo com sinal sonoro/visual e acionamento por botão e/ou um funcionário responsável pela trânsito e travessia dos pedestres.

- As plataformas de desembarque e embarque devem ter mesma altura do acesso dos ônibus podendo ter uma diferença máxima de 1,5cm para garantir um embarque em nível.

- Toda a plataforma deve ser protegida contra as intempéries naturais. A cobertura deve proporcionar a proteção em toda plataforma dos raios solares e da chuva. As portarias devem ser localizadas próximo aos portões de acesso dos veículos de modo a garantir o controle de entrada e saída. Impedindo o acesso indevido de pedestres e veículos não autorizados.

- Os terminais devem ser projetados de forma sustentável, com programas de funcionamento sustentável. Coletas de lixo seletivas, aproveitamento das águas pluviais, usam de iluminação por LED, uso de energias renováveis são caminhos para atingir essa diretriz.

- Os terminais devem possuir TVs com informações educativas, sobre o tempo, trânsito e notícias pertinentes em geral, além de poder ser utilizada para publicidade arrecadando fundos para a manutenção própria. Painéis de informação sobre horários de chegada, partida, itinerários e atrasos devem ser instalados em cada local de embarque. Essas informações também devem estar disponíveis no site e por aplicativos para celulares.

- Os organizadores de fila devem proporcionar acesso aos portadores de deficiência, idosos e gestantes, possibilitando a preferência no embarque. Além de assentos adequados e espaço para cadeirantes durante a espera.

- Os terminais devem possuir geradores que supram ao menos as funções básicas de iluminação, elevadores e bilheterias.

- Os pisos devem ser antiderrapantes e planos em qualquer situação garantindo segurança e acessibilidade.

- Os terminais devem possuir no mínimo um acesso de entrada e saída independentes, melhorando assim o fluxo e diminuindo o risco de colisões. 


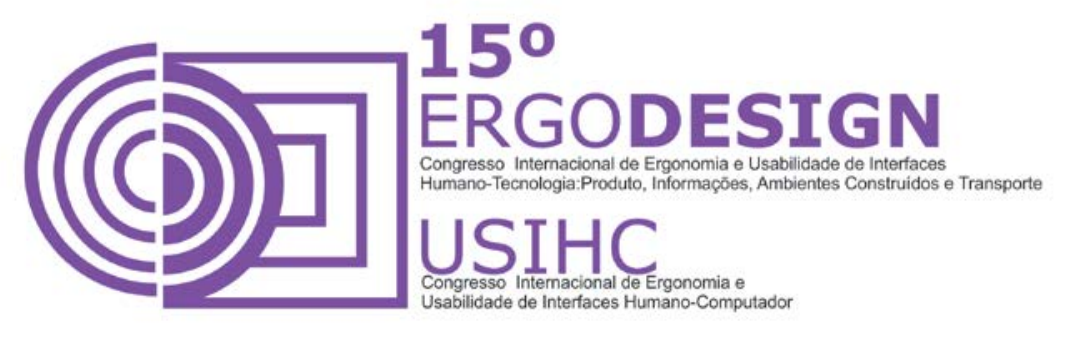

- Os organizadores de fila devem ter dimensão compatível ao tamanho máximo que as filas atingem. Possuir apoio confortável para espera evitando que sejam utilizados como banco.

- Devem ser planejados locais de descanso e convivência para os passageiros e para os funcionários.

- As áreas de desembarque devem ser dimensionadas considerando o fluxo máximo dos veículos e futuras ampliações de frota. Esses locais devem ser restritos apenas aos passageiros que realizam o desembarque. Não sendo permitido que os passageiros embarquem nesses locais.

- As vias devem possuir sinalização de transito indicando velocidade máxima, sentido do tráfego, preferências, locais proibidos de estacionar e/ou parar, entre outras regras necessárias para um fluxo dos veículos de forma segura e mais fluida possível. É aconselhável o uso de equipamentos eletrônicos para monitorar o a velocidade dos veículos.

- Deve ser criado um sistema de monitoramento dos coletivos por GPS, garantindo horários mais precisos, cumprimento do itinerário e verificando inconsistências do sistema de transporte.

- O quantitativo de ônibus por linha deve ser adequado a demanda de passageiros garantindo conforto e segurança no embarque, desembarque e durante todo o percurso da viagem. O uso de ônibus articulados ou biarticulados em horários de pico pode viabilizar essa diretriz.

- Deve ser criada para os terminais a função do orientador de tráfego, ou seja, funcionários responsáveis por orientar os ônibus nas manobras de embarque e desembarque, controle da velocidade e respeito a faixa de pedestre.

- Todos os terminais devem oferecer serviço de assistência ao idoso, gestante e pessoa com deficiência. Oferecendo orientação, locomoção e comunicação. Os terminais devem possuir materiais de primeiros socorros e equipe treinada para utilizá-lo caso ocorra emergências.

\section{CONDIDERAÇÕES FINAIS}

Com o estudo da ergonomia e verificando que os terminais são ambientes construídos destinados a abrigar os usuários nas diversas atividades relacionadas ao transbordo entre os coletivos, verificou-se que a avaliação e o estudo ergonômico são a as melhores formas de se estabelecer diretrizes e parâmetros para o maior conforto e segurança na relação de uso desses terminais, tornando-os mais humanos e adequados a suas funções.

Com a pesquisa foi possível propor diretrizes relacionadas aos aspectos projetuais e organizacionais que são capazes de garantir um melhor conforto, maior facilidade na realização das atividades do terminal e melhorar as questões relacionadas à segurança, além de contribuir para um melhor relacionamento interpessoal entre os usuários dos terminais, sejam eles funcionários ou passageiros.

Compreender a complexidade de fatores envolvidos nas relações encontradas no terminal foi fundamental para a concepção desses ambientes atendendo as especificidades e expectativas de seus usuários, assim como as atividades exercidas por eles nos seus espaços. Através do 


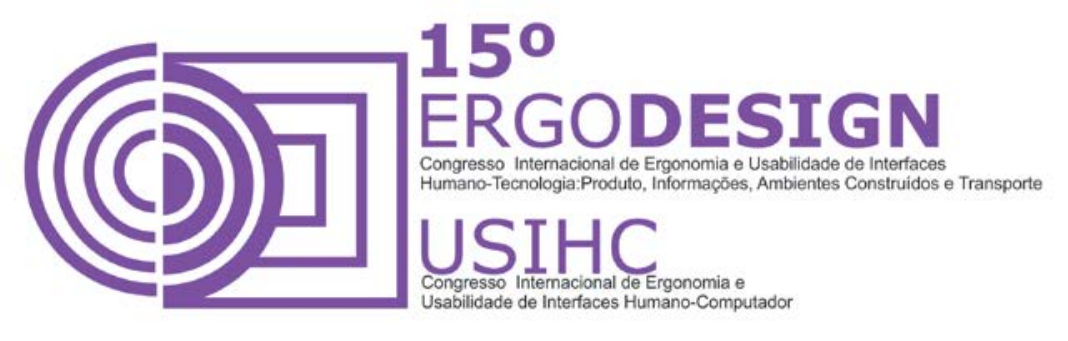

diagnóstico ergonômico realizado foi possível verificar que os terminais necessitam de um planejamento mais adequado, de uma infraestrutura projetada focada também para os seus usuários e que ocorra uma conscientização e fiscalização para o cumprimento das regras estabelecida para evitar o que frequentemente ocorre como as grandes filas, tumulto, risco de acidentes, falta de acessibilidade e outros constrangimentos.

Com as propostas de diretrizes sugeridas pela pesquisa foi verificado que muitas delas exigem um custo baixo para o Estado e podem gerar benefícios muito maiores para a população e até mesmo um retorno econômico para Pernambuco.

Atualmente a forma como é apresentado os equipamentos de transporte público, no caso os terminais de integração da RMR, só estimulam a população a procurar outros meios de locomoção como: transportes irregulares, adquirir veículos particulares ou até mesmo pagar mais de uma passagem para não ter que enfrentar os desconfortos de um terminal de integração. É indispensável implantar um transporte público que seja competitivo que tenha um desempenho equivalente ou superior a outros meios de transporte urbano. Ser flexível e rápido para competir com as motos, e ser confortável, confiável e seguro como um carro e que permita evitar congestionamentos. Além de oferecer tarifas muito competitivas (GUTIÉRREZ, 2014).

Com este estudo, pode-se afirmar que os terminais de integração são inadequados aos requisitos humanos dos seus usuários, causando constrangimentos diários a população que depende dele para sua mobilidade. Estudos ergonômicos em terminais de integração podem contribuir significativamente para tornar esses ambientes mais adequados aos fatores humanos e estabelecendo uma relação mais adequada, acessível, confortável, segura e eficiente.

\section{REFERÊNCIAS}

Bolfarine, H. e Bussab, W. O. Elementos de amostragem. Edgard Blücher, 2005.

CADAVAL, Maurício. Manifestações Sociais e Transporte Público. Associação Nacional das Empresas de Transportes Urbanos. In: Anuário NTU: 2013 - 2014 / Associação Nacional das Empresas de Transportes Urbanos. - Brasilia: NTU, 2014.

FURTADO, Marcelo. 2013. Por um transporte público acessível. Disponível em <http://www.greenpeace.org/brasil/pt/Noticias/Pelo-direito-a-manifestacao-nao-violenta/>. Acessado em 19 de outubro de 2013.

IIDA, Itiro. Ergonomia: Projeto e Produção. $2^{\mathrm{a}}$ Ed. rev e ampl. São Paulo:Blucher, 2005.

MARTINS, L. M. et al. Análise ergonômica comparativa de cozinhas residenciais com arranjos físicos diferenciados. In: Anais do ERGODESIGN 2006: Congresso Internacional de Ergonomia e Usabilidade de Interfaces Humano-Tecnologia. 6, Bauru, São Paulo. 2006.

MDT, Movimento Nacional pelo Direito ao Transporte Público de Qualidade para Todos; O Que é Mobilidade Urbana?; Mobilidade Urbana e Inclusão Social, Brasília, 2009.

VILLAROUCO, Vilma. An ergonomic look at the work environment. In: Anais do 17th World Congress on Ergonomics, Beijing, China. 2009. 